\title{
Static site indices from different national forest inventories: harmonization and prediction from site conditions
}

\author{
Susanne Brandl ${ }^{1} \cdot$ Tobias Mette $^{1} \cdot$ Wolfgang Falk $^{1} \cdot$ Patrick Vallet $^{2,3} \cdot$ Thomas Rötzer $^{4} \cdot$ Hans $^{\text {Pretzsch }}{ }^{4}$
}

Received: 27 October 2017 / Accepted: 18 April 2018 / Published online: 7 May 2018

(C) INRA and Springer-Verlag France SAS, part of Springer Nature 2018

\begin{abstract}
- Key message Static site indices determined from stands' top height are derived from different forest inventory sources with height and age information and thus enable comparisons and modeling of a species' productivity encompassing large environmental gradients.

- Context Estimating forest site productivity under changing climate requires models that cover a wide range of site conditions. To exploit different inventory sources, we need harmonized measures and procedures for the productive potential. Static site indices (SI) appear to be a good choice.

- Aims We propose a method to derive static site indices for different inventory designs and apply it to six tree species of the German and French National Forest Inventory (NFI). For Norway spruce and European beech, the climate dependency of SI is modeled in order to estimate trends in productivity due to climate change.

- Methods Height and age measures are determined from the top diameters of a species at a given site. The SI is determined for a reference age of 100 years.

- Results The top height proves as a stable height measure that can be derived harmoniously from German and French NFI. The boundaries of the age-height frame are well described by the Chapman-Richards function. For spruce and beech, generalized additive models of the SI against simple climate variables lead to stable and plausible model behavior.

- Conclusion The introduced methodology permits a harmonized quantification of forest site productivity by static site indices. Predicting productivity in dependence on climate illustrates the benefits of combined datasets.
\end{abstract}

This article is part of the topical collection on Environmental data for the German NFI

Handling Editor: Jean-Michel Leban

Contribution of the co-authors

Susanne Brandl: $55 \%$ data preparation and analysis, literature research, responsible for methods, results, and discussion. Tobias Mette: $25 \%$ concept, literature research, responsible for introduction, and proofreading. Wolfgang Falk: $5 \%$ consulting and proof reading. Patrick Vallet: $5 \%$ consulting and proof reading. Thomas Rötzer: $5 \%$, consulting and proof reading. Hans Pretzsch: $5 \%$ consulting and proofreading

Susanne Brandl

susanne.brandl@lwf.bayern.de

Tobias Mette

tobias.mette@1wf.bayern.de

Wolfgang Falk

wolfgang.falk@1wf.bayern.de

Patrick Vallet

patrick.vallet@irstea.fr

Thomas Rötzer

thomas.roetzer@1rz.tum.de
Hans Pretzsch

hans.pretzsch@1rz.tum.de

1 Bavarian State Institute of Forestry, Hans-Carl-von-Carlowitz-Platz 1, 85354 Freising, Germany

2 Univ. Grenoble Alpes, Irstea, UR EMGR, 2 rue de la Papeterie - BP 76, F-38402 St-Martin-d'Hères, France

Irstea, UR EFNO, Domaine des Barres, F-45290 Nogent-sur-Vernisson, France

4 Forest Growth and Yield Science, Technische Universität München, Hans-Carl-von-Carlowitz-Platz 2, 85354 Freising, Germany 
Keywords National forest inventories $\cdot$ Climate $\cdot$ Productivity

\section{Introduction}

Forest site conditions are not static. Changes in site conditions due to climate change lead to changes in potential productivity. As potential productivity constitutes key information for timber-oriented forestry or the estimation of carbon stocks, it is important to estimate future trends. Prerequisites for this are databases containing large environmental gradients and a suitable measure for potential productivity. In the history of forestry, phytocentric approaches have dominated (Bontemps and Bouriaud 2014) as formulated, e.g., in Assmann (1961: 154): "Since estimates of the potential productivity based on soil characteristics and climate are afflicted with high uncertainty, it is necessary to rely on measures of the growing stand itself'. The German forest scientist von Baur postulated already in 1881 that mid height is "the most precise and only correct indicator not solely for the assessment of a [...] stand but for its site class [German: Standortbonität]." This postulate meant a remarkable change in forest growth and yield science: the yield development is estimated through height and age information. What helped to manifest von Baur's postulate was that Eichhorn (1902) showed for silver fir experimental plots in South-West Germany that "independent of the site, a certain mid height corresponds to a certain stand mass" [in forestry, at that time, mass was a synonym for volume yield]. The law of Eichhorn was amended by Gehrhardt (1909), who recommended substituting yield by total yield (including thinnings), and by Assmann (1961), who recommended substituting mid height by top height. Both modifications made Eichhorn's law more stable against thinning, especially from below (for summaries see Skovsgaard and Vanclay 2008; Pretzsch 2009; Bontemps and Bouriaud 2014).

Since the late eighteenth century, thousands of yield tables for hundreds of species have been compiled all over the world (e.g., Schober 1995; Vannière 1984). Common to all yield tables is the differentiation of site classes defined by a spectrum of age-height trajectories. The site index refers to the height at a specific reference age. For long-lived temperate forestry species, the reference age is typically 100 years. Yield tables were designed to represent regional growth behavior of a species and to allow estimating the site index of a given stand. However, for a long time, it was not considered that site conditions change, especially climate conditions.

While old stands stay well within the height frame of the yield tables, young stands clearly exceed the given height frame (Fig. 1; see also Röhle 1997, resp. Pott 1997 in Pretzsch 2009, pp. 557 resp. 584). This is not because younger stands have been systematically planted at better sites but because they have experienced better growing conditions on the same sites. Any model that relates a site index based on yield tables to recent site condition data would be afflicted with an age trend: on the same site, young stands would be assigned a higher yield class and thus a better site quality than old stands. The realization that site conditions are not constant and that non-table conforming growth is rather the rule than the exception, questions how reliably a site can be classified by yield tables (Skovsgaard and Vanclay 2013; emphasis on enhanced growth due to climate change: Spiecker 1999; Pretzsch et al. 2014).

Against this background, we derive a static site index. By $<$ static $>$, we refer to the idea of generating false or pseudo age-height trajectories from momentary data of different ages (as in von Baur's original strip method; in German: Streifenbonitierung). This is done by dividing large data sets of age-height measurements into even spaced age-height curves. Unlike the yield tables, these static height curves do not represent true trajectories of the stands' height development since, under changing site conditions, a space-for-time substitution is biased (Yue et al. 2016; sensu lato Pickett 1989). However, the static height curves effectively lead to a balanced site index distribution over the age spectrum and make site index models stable against age trends.

Over the last decades, it has become very popular to develop statistical models that explain site index in dependence on environmental variables with varying spatial scales (Bontemps and Bouriaud 2014; e.g., Germany: Albert and

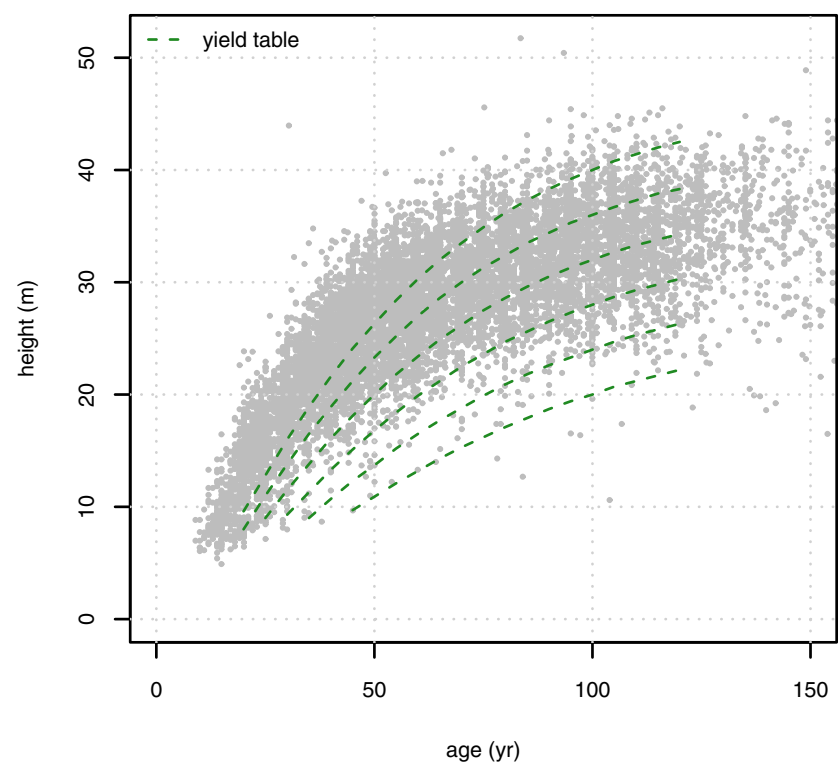

Fig. 1 Age-height measurements of dominant Norway spruce trees in the third German National Forest Inventory 2012 along age-height development for different site indices of spruce yield tables from 1963 (Assmann and Franz) 
Schmidt 2010; Nothdurft et al. 2012; France: Seynave et al. 2005; Seynave et al. 2008). Many large-scale studies are based on national forest inventories. Since 10-15 years ago, national inventories have provided an increasingly accessible data source of high quality and representation. A joint effort to harmonize national forest inventories has been undertaken in McRoberts et al. (2012) and Tomppo et al. (2010). The methods and methodologies developed focused mainly on forest carbon and biodiversity estimation.

This study relates to these efforts as we harmonize site indices and the underlying height and age measures of two publicly accessible NFI data sets: Germany and France. We harmonized site indices for six species: Norway spruce (Picea abies (L.) Karst.), Scots pine (Pinus sylvestris L.), Douglas-fir (Pseudotsuga menziesii (Mirbel) Franco), European beech (Fagus sylvatica L.), sessile oak (Quercus petraea (Mattuschka) Liebl.), and pedunculate oak (Quercus robur L.). Then, we pushed forward the analyses for two species, spruce and beech, to analyze their SI modulation by environmental variables. The methodology that we introduce is transferable to other species and inventory designs as well. The combination of different inventories is extremely promising as it can cover substantially larger parts of a species' distribution and distribution limits than a single inventory alone (Brus et al. 2012; Nabuurs et al. 2013; Dolos et al. 2016). This is an important premise to derive stable species-specific models that predict the site index as a measure of growth potential from site conditions.

In summary, the aims of the study were (1) to derive a harmonized static site index based on German and French NFI data and (2) to estimate trends in productivity due to climate change.

\section{Material and methods}

\subsection{National forest inventory data}

In Germany, the NFI is based on a permanent nationwide $4 \mathrm{~km} \times 4 \mathrm{~km}$ grid (regionally densified). Each grid point represents an inventory cluster of four inventory points laid in a square of $150 \mathrm{~m}$ edge length. Each inventory point in forest area is the center of an angle-count sampling and sample circles with defined radii (BMELV 2011). In this study, the data of the third NFI (2012) are used. In France, since 2010, the NFI is based on a $1 \mathrm{~km} \times 2 \mathrm{~km}$ grid surveyed over a 5 -year rotation. Each grid point is the center of three subplots of 6, 9, and $15 \mathrm{~m}$, respectively, where trees that reach certain diameter thresholds are included (IGN 2016). In this study, data from 2006 until 2013 are used. From the NFI data, we selected all inventory plots where the investigated species accounted for $\geq 70 \%$ of the plot basal area. Plots in forests with no defined structure and coppice plots were discarded as well as plots with a coefficient of variation of age $>0.25$. For Norway spruce, this resulted in 10,552 plots in Germany and 914 plots in France. For European beech, 5247 plots in Germany and 1595 plots in France were selected. Trees with top or crown breakage or other severe damages were not counted among the dominant trees.

\subsection{Top height and age}

The top height $h_{\text {top }}$ is defined as the height corresponding to the root mean square diameter $d_{\text {top }}$ of the top 100 diameters of a tree species on a site (Kramer and Akça 1995). The estimate of $h_{\text {top }}$ depends in the first place on the representativeness of the sampled trees for the entire stand. Each sample tree stands for a certain number of trees per hectare, which depends on the tree's DBH. Arguing that each sample tree represents a DBH distribution rather than a single value, a density function was laid over the DBH distribution, i.e., a bandwidth filter was applied to the DBH histogram (Fig. 2). The bandwidth scales the width of this distribution and equals the standard deviation of the normal function in a Gaussian kernel (Venables and Ripley 2002). The corresponding $h_{\text {top }}$ was derived from species-specific uniform height-diameter curves (Dahm 2006).

In the German NFI, the age of all sample trees is given, but the source and quality of the age information differ (records of planting, increment boring, estimation etc.). In the French $\mathrm{NFI}$, only the age at breast height of one or two dominant trees is determined by increment boring. The age corresponding to $d_{\text {top }}$ and $h_{\text {top }}$ was calculated as the mean age of the top 100

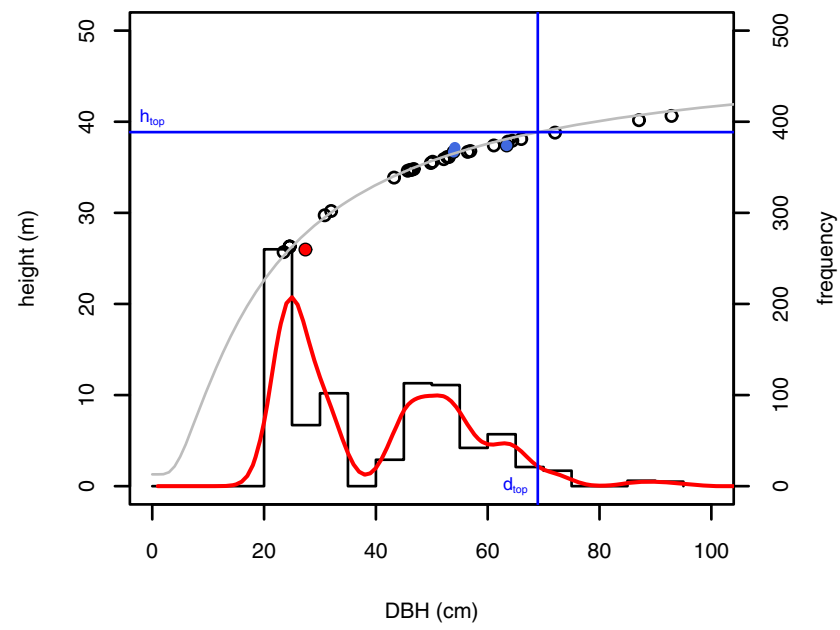

Fig. $2 d_{\text {top }}$ and $h_{\text {top }}$ estimation visualized for an exemplary spruce plot of the German NFI: The circles mark height and DBH of trees included in the sample. Trees with measured heights are plotted blue. The red dot corresponds to a tree with crown breakage. The uniform height-diametercurve is overlaid in gray. The histogram shows the number of trees per hectare represented by the sampled tree of a certain DBH. The red line shows the density of the DBH distribution 
trees of the investigated species for the German NFI sample. For the French NFI sample, the age at breast height of the trees of the investigated species with age measurements was averaged and adjusted for the missed tree rings between 0 and $130 \mathrm{~cm}$ height according to previous measurements from the French NFI.

\subsection{Static site index determination}

To obtain the site index (SI), the age-height spectrum has to be divided into infinite sets of adjacent age-height curves. To do so, we fitted the Chapman-Richards function (Richards 1959) to the 5 and the $95 \%$ quantiles of heights creating a lower and upper boundary line (Fig. 3).

$h_{\text {top }(i)}=A^{*}\left(1-e^{-k * a g e_{i}}\right)^{p}$

The SI is determined by scaling the position of $h_{\text {top }}(i)$ between lower and upper boundary height at age $i$ with the ratio of the span between lower and upper boundary height at age 100 and the span between lower and upper boundary height at age $i$ :

$\hat{S I}=h_{\text {top } l(100)}+\left(h_{\text {top }(i)}-h_{\text {top } l(i)}\right) \cdot \frac{h_{\text {top } u(100)}-h_{\text {top } l(100)}}{h_{\text {top } u(i)}-h_{\text {top } l(i)}}$

with $h_{\mathrm{top} l}$ and $h_{\mathrm{top} u}$ as the lower and upper boundary height at the respective age.

As indicated in the introduction, we did not develop a height growth model here. Our aim was to determine stable

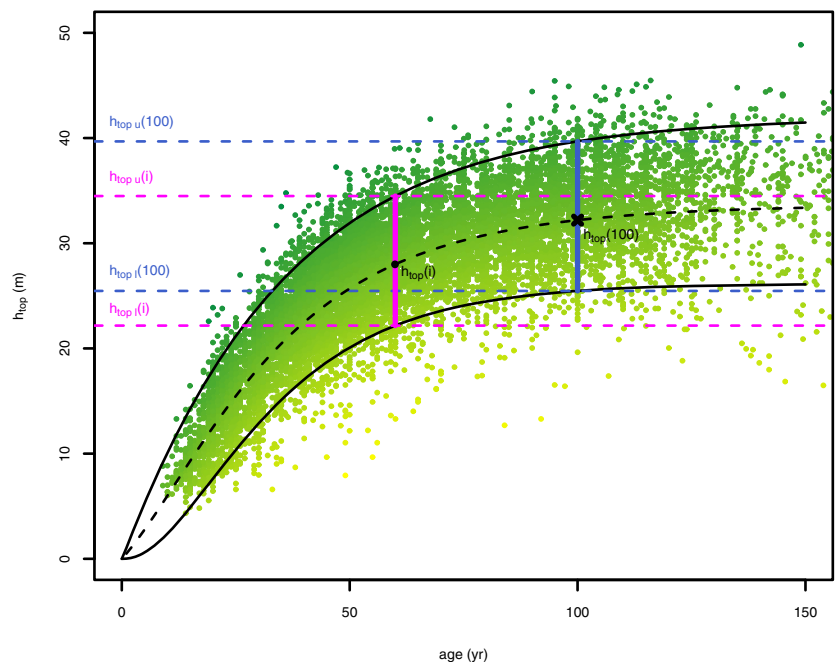

Fig. 3 Illustration of translating the top height $h_{\text {top }}(i)$ of a species in a stand at age $i$ to the corresponding height $h_{\text {top }}(100)$ at the reference age of 100 years, i.e., the SI; green points mark heights and ages of NFI spruce plots; the solid black curves show the fit of the Chapman-Richards function to the 5 and $95 \%$ quantiles; the black dot marks an example stand at age 60 with a top height of $28 \mathrm{~m}$. The black cross marks its translation to $h_{\text {top }}$ at age 100 , resulting in a SI of about $32 \mathrm{~m}$ lower and upper boundary lines of the age-height distribution in the data in order to determine the SI of each stand by comparing its top height with a reference of the same age. We employed the Chapman-Richards function instead of polynomials because its properties allow a stable fit of lower and upper boundary lines over the whole age range. However, these lines represent true trajectories of the stands' height development over time only if growth conditions are assumed to be stable. If we assume improving growth conditions over the last century - for which evidence is ample (cf. introduction) young stands will grow faster, i.e., with higher site indices, than old stands which experienced less favorable growing conditions when young. The static site index thereby avoids an age trend in the site indices and makes young and old stands on similar sites comparable.

\subsection{Error estimation from virtual data}

We used virtual stands, which were simulated based on yield tables of Norway spruce, to assess the uncertainties in deriving the static site index. A detailed description of methods and results as well as a discussion of the uncertainties associated with the static site index formation are presented in Appendix 1.

\subsection{Modeling site index in dependence on environmental variables}

The second aim of the study was to model SI in dependence on climate parameters and predict the potential productivity of a tree species under climate change. We used the climate data of WordClim which cover the study area with a resolution of 30 arcseconds, i.e., approximately $1 \mathrm{~km}$ (Hijmans et al. 2005). Climate variables (Table 1) were grouped into variables characterizing mean annual temperature or summer temperature, winter temperature, precipitation, and continentality. Elevation was used as an additional explanatory variable. In order to prevent high correlations, only one variable could be selected from each group.

We did not include soil parameters in the models, since it is difficult to derive comparable soil parameters for the German and French inventory plots. The influence of soil parameters was taken into account only by removing plots where the climate signal was likely to be confounded by extreme soil characteristics (gley soils, pseudogley soils, moor soils, extremely shallow soils (depth $<35 \mathrm{~cm}$ ), and soils with skeleton content $>90 \%$ ). For Germany, the soil data were raised within the project "Forest productivity, Carbon sequestration, Climate change". For France, information on soil parameters forms part of the NFI data. We compared the differences in model performance caused by applying these soil filters.

We fitted generalized additive models with a gamma error distribution and log-link function (Wood 2006; Pya 
Table 1 Characterization of the environmental variables for spruce and beech plots used for model fitting

\begin{tabular}{|c|c|c|c|c|c|c|}
\hline & & & \multicolumn{2}{|l|}{ Spruce } & \multicolumn{2}{|l|}{ Beech } \\
\hline & & & Mean & SD & Mean & SD \\
\hline \multirow[t]{5}{*}{ Summer/annual temperature } & Mean annual temperature $\left({ }^{\circ} \mathrm{C}\right)$ & $\mathrm{T}$ & 7.4 & 1.1 & 8.4 & 1.2 \\
\hline & Mean temperature warmest quarter $\left({ }^{\circ} \mathrm{C}\right)$ & T_wq & 15.4 & 1.2 & 16.1 & 1.1 \\
\hline & Mean temperature May to Sept. $\left({ }^{\circ} \mathrm{C}\right)$ & T_5to9 & 14.1 & 1.2 & 14.7 & 1.1 \\
\hline & Max. temperature warmest month $\left({ }^{\circ} \mathrm{C}\right)$ & Tmax_wm & 21.3 & 1.5 & 22.1 & 1.4 \\
\hline & Mean July temperature $\left({ }^{\circ} \mathrm{C}\right)$ & $\mathrm{T} 7$ & 16.2 & 1.2 & 16.8 & 1.1 \\
\hline \multirow[t]{2}{*}{ Winter temperature } & Mean January temperature $\left({ }^{\circ} \mathrm{C}\right)$ & $\mathrm{T} 1$ & -1.5 & 1.4 & -0.2 & 1.6 \\
\hline & Min. temperature coldest month $\left({ }^{\circ} \mathrm{C}\right)$ & Tmin_cm & -4.2 & 1.5 & -2.9 & 1.5 \\
\hline \multirow[t]{3}{*}{ Precipitation } & Annual precipitation sum (mm) & $\mathrm{P}$ & 882 & 176 & 831 & 147 \\
\hline & Precipitation sum warmest quarter (mm) & P_wq & 270 & 54 & 238 & 42 \\
\hline & Precipitation sum May to Sept. (mm) & P_5to9 & 420 & 80 & 382 & 63 \\
\hline \multirow[t]{3}{*}{ Continentality } & Continentality index (Conrad 1946) & ci & 36.5 & 3.8 & 35.7 & 3.6 \\
\hline & Tmax_wm-Tmin_cm $\left({ }^{\circ} \mathrm{C}\right)$ & Txn_range & 25.6 & 1.7 & 25 & 1.6 \\
\hline & T_wq-T1 $\left({ }^{\circ} \mathrm{C}\right)$ & T_range & 17 & 1.2 & 16.3 & 1.3 \\
\hline Elevation & Elevation (m) & Elevation & 564 & 278 & 472 & 315 \\
\hline
\end{tabular}

and Wood 2015) using $\mathrm{R}$ version 3.3.2 and the R packages $\mathrm{mgcv}$ and scam. For model fitting, only plots with mean ages of the top 100 trees between 30 and 150 years were used. The intercept could differ between Germany and France in order to account for possible effects of differences in inventory design not yet considered. We selected the best model of all possible combinations using adjusted $R^{2}$ and AIC as criteria. We checked for trends in the residuals by plotting them against the covariates and the fitted values. Additionally, we checked for spatial trends in the residuals by mapping them.

\section{Results}

\subsection{Static site index determination}

Figure 4 displays age-height scatter plots and the fits of the Chapman-Richards function for Norway spruce and European beech from the joint data sets of the German and French NFI. Results for Scots pine, Douglas-fir, sessile oak, and pedunculate oak are presented in Appendix 2. Table 2 summarizes the function parameters for the joint data set. The asymptotes (A) of the upper boundary line are lower than the maximum top heights observed, as they were fitted with $95 \%$ quantile regressions. The fitted upper and lower boundary lines describe well the range of top heights over the whole age range, which was a prerequisite for deriving the static site index.

\subsection{Error estimation from virtual data}

Tests made on virtual data ensured that there are no big or systematic deviations resulting from the two NFI sampling methods and that $h_{\text {top }}$ is relatively stable with respect to effects of density. The effect of age errors on SI estimation decreases with increasing age. Detailed results are presented in Appendix 1.

\subsection{Site index dependency on environmental variables}

We investigated how far environmental variables contribute in explaining the site index. Tables 3 and 4 summarize the results of SI models for Norway spruce and European beech respectively. Filtering the data for extreme soil conditions increases the adjusted $R^{2}$ (spruce: from 0.164 to 0.191 ; beech: from 0.335 to 0.401 ).

\subsubsection{Spruce}

The generalized additive model for spruce can be described with:

$S I_{\mathrm{GAM}}$, Spruce $=\exp \left(f\left(T_{-} 5\right.\right.$ to 9$)+f(T 1)+f(P)+$ country $\left.+\varepsilon\right)(3)$

Mean temperature of the growing season from May to September ( $\mathrm{T}$ 5to9), mean temperature in January (T1), and annual precipitation sum (P) were selected to explain SI of Norway spruce. Graphical checks revealed no trends in the residuals. T 5 to9 has the strongest explanatory power (Fig. 5a). It has a positive effect on SI over the whole range. 

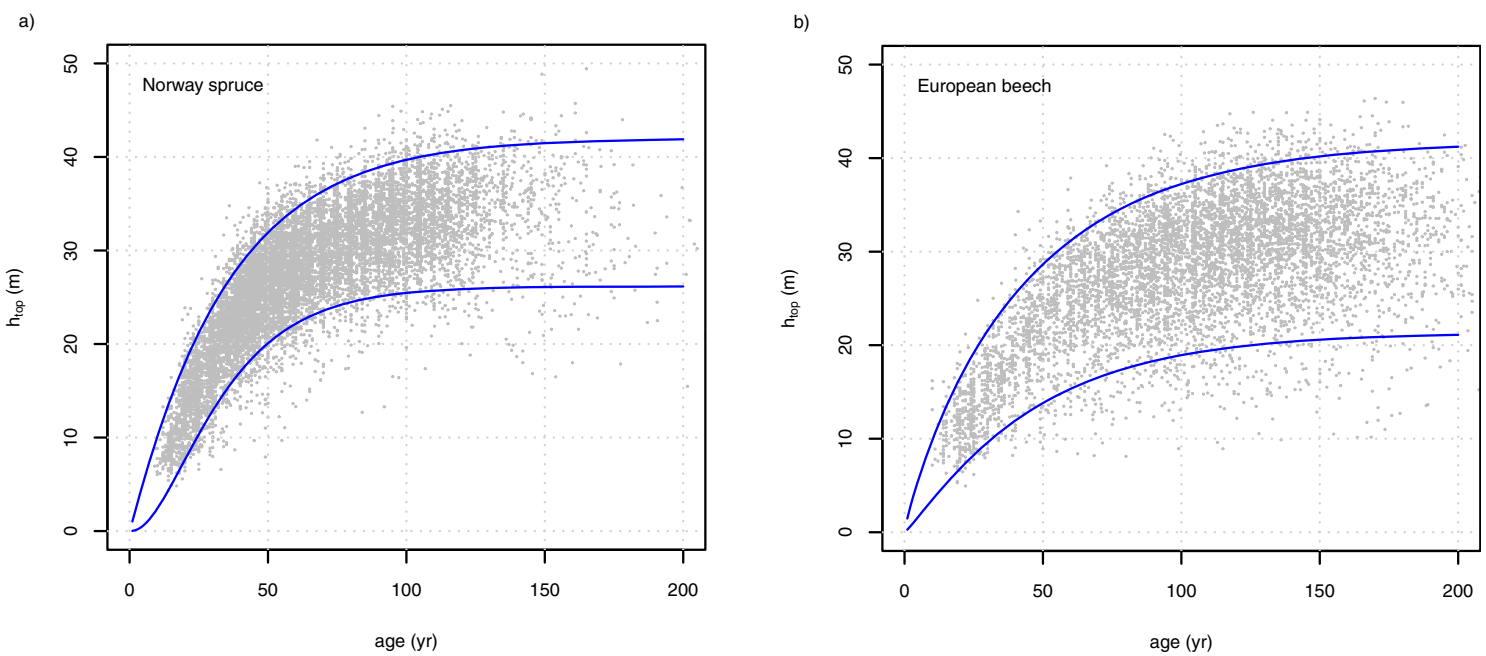

Fig. 4 Age-height scatter plots for Norway spruce and European beech in the German and French NFI data. Lines depict quantile regression for the 5 and 95\% percentiles with the Chapman-Richards function

Until approximately $15{ }^{\circ} \mathrm{C}$, SI increases strongly with rising temperatures. A further increase in $\mathrm{T}$-5to9 leads only to a very slight increase in SI. The confidence intervals become wide for T_5 to $9>16^{\circ} \mathrm{C}$, i.e., the uncertainty in model predictions is high at the warm temperature margin. Overall SI decreases with rising T1 (Fig. 5b). For T1 $>-1{ }^{\circ} \mathrm{C}$, a continuous decrease is fitted. Due to the wide confidence intervals at the cold margin of T1, one could either assume no effect of T1 on SI below $-1{ }^{\circ} \mathrm{C}$ or a decrease in SI with rising $\mathrm{T} 1$ over the whole range of the variable. There is a steep increase in SI with $\mathrm{P}$ until a threshold value of about $750 \mathrm{~mm}$ is reached (Fig. 5c). Even at the very dry margin, the confidence intervals remain narrow, i.e., this effect is clearly present in the data. At the threshold value of $750 \mathrm{~mm}$ saturation is reached and the effect of Psum stays more or less level until a value of about $1100 \mathrm{~mm}$. The effect of the country factor is rather small (Table 3).

In order to help interpret the effect of temperature on SI, we fitted the same model except that T_5to9 and T1 entered the model as an interaction term (Fig. 5d). At the cold edge (lower left corner), the contour lines are more or less vertical, i.e., only T_5to9 influences SI. Towards warmer summers, the SI increases but the increase is stronger when winters stay colder

Table 2 Results of fitting the Chapman-Richards function to the lower $5 \%$ and the upper $95 \%$ percentiles of the age-height distribution for the joint German and French inventory data

\begin{tabular}{llll}
\hline Quantile curve & Parameter & Spruce & Beech \\
\hline Lower & $A=$ & 26.16 & 21.35 \\
& $k=$ & 0.0448 & 0.0232 \\
& $p=$ & 2.35 & 1.15 \\
Upper & $A=$ & 42.01 & 41.79 \\
& $k=$ & 0.0294 & 0.0208 \\
& $p=$ & 1.05 & 0.86 \\
\hline
\end{tabular}

(lower right corner; continental climate) than under warm (oceanic) winter conditions (upper right corner).

\subsubsection{Beech}

The generalized additive model for beech can be described with:

$S I_{\mathrm{GAM}, \text { Beech }}=\exp \left(f\left(T_{\_} w q\right)+f\left(P \_5 t o 9\right)+f(\right.$ elevation $)+$ country $\left.+\varepsilon\right)$

Mean temperature of the warmest quarter (T_wq), precipitation sum during the growing season from May to September (P_5to9), and elevation were selected to explain SI of European beech. Graphical checks revealed no trends in the residuals. For T_wq, a curve with a wide optimum range between about 14 and $18{ }^{\circ} \mathrm{C}$ is fitted (Fig. 6a). SI increases strongly with rising $\mathrm{T}$ _wq until about $14{ }^{\circ} \mathrm{C}$. There is a slight further increase in SI until about $16^{\circ} \mathrm{C}$ when it is more or less level and reaches the optimum at $17.2{ }^{\circ} \mathrm{C}$ before it decreases again for T_wq $>17.5^{\circ} \mathrm{C}$. A saturation curve can be fitted to P_5to9 (Fig. 6b). SI slowly starts increasing at P_5to9=

Table 3 Site index model performance for Norway spruce

\begin{tabular}{lllll}
\hline & Estimate & Standard error & $T$ statistics & $p$ value \\
Intercept & 3.473 & 0.005 & 633.864 & $<2 \times 10^{-16}$ \\
$\begin{array}{l}\text { country factor } \\
\text { (Germany) }\end{array}$ & 0.029 & 0.006 & 4.749 & $2.12 \times 10^{-6}$ \\
& edf & Ref. df & $F$ statistics & $p$ value \\
$\mathrm{s}(\mathrm{T}$ 5to9) & 4.943 & 6.077 & 87.48 & $<2 \times 10^{-16}$ \\
$\mathrm{~s}(\mathrm{~T} 1)$ & 6.058 & 7.131 & 14.28 & $<2 \times 10^{-16}$ \\
$\mathrm{~s}(\mathrm{P})$ & 7.906 & 8.667 & 12.94 & $<2 \times 10^{-16}$ \\
Adjusted $R^{2}$ & 0.191 & \multicolumn{5}{c}{$\begin{array}{c}\text { Deviance } \\
\text { explained }\end{array}$} \\
& \multicolumn{5}{c}{$19.6 \%$} \\
\hline
\end{tabular}

$e d f$ estimated degrees of freedom 
Table 4 Site index model performance for European beech

\begin{tabular}{lllll}
\hline & Estimate & Standard error & $T$ statistics & $p$ value \\
Intercept & 3.228 & 0.030 & 106.4 & $<2 \times 10^{-16}$ \\
$\begin{array}{c}\text { Country factor } \\
\text { (Germany) }\end{array}$ & 0.131 & 0.009 & 15.0 & $<2 \times 10^{-16}$ \\
& edf & Ref. df & $F$ statistics & $p$ value \\
s(T_wq) & 6.250 & 7.197 & 9.684 & $4.1 \times 10^{-12}$ \\
s(P_5to9) & 2.743 & 3.048 & 24.544 & $9.07 \times 10^{-16}$ \\
s(elevation) & 7.919 & 8.593 & 40.596 & $<2 \times 10^{-16}$ \\
Adjusted $R^{2}$ & 0.4013 & \multicolumn{5}{c}{$\begin{array}{c}\text { Deviance } \\
\text { explained }\end{array}$} \\
& \multicolumn{5}{c}{$41.6 \%$} \\
\end{tabular}

$e d f$ estimated degrees of freedom

$300 \mathrm{~mm}$. Between 380 and $520 \mathrm{~mm}$, there is a steep increase, which flattens at a threshold value of about $570 \mathrm{~mm}$. The effect of P 5to9 or variables characterizing precipitation in general is not as clear as the effects of the other variables.
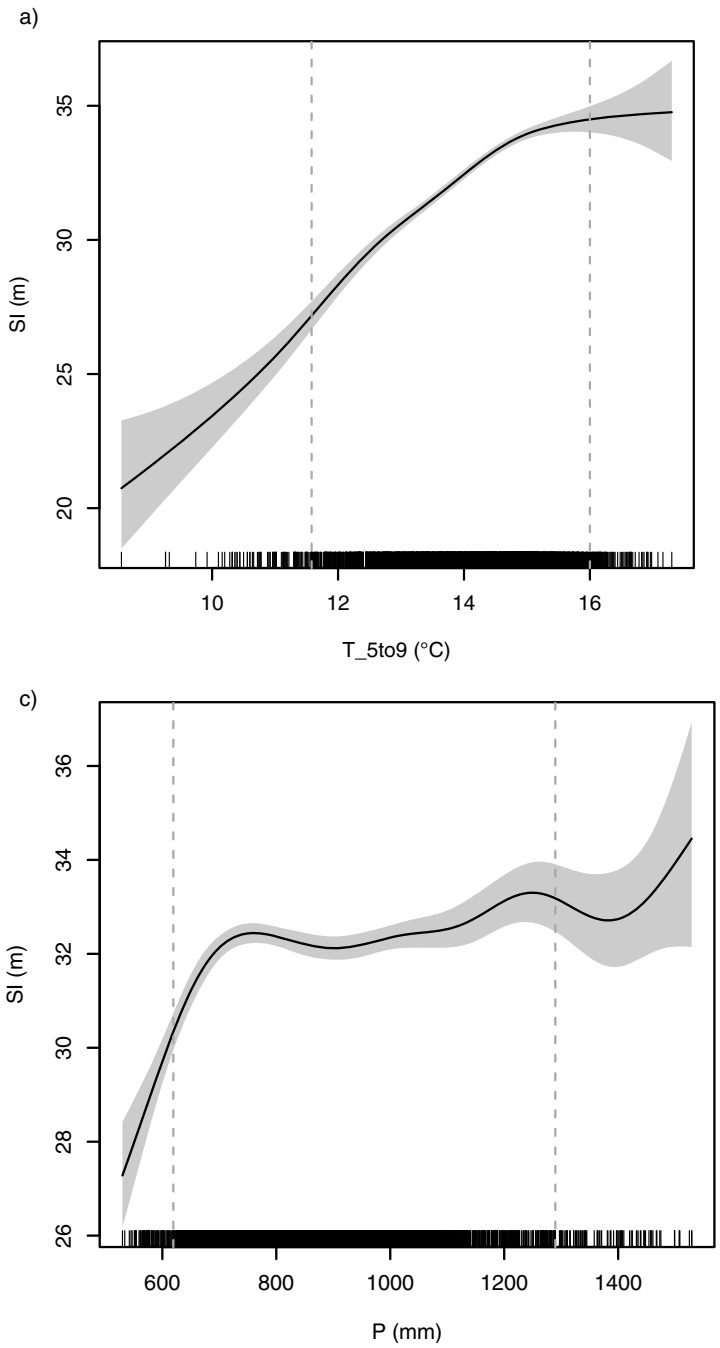

Fig. 5 Effects of T_5to9 (a), T1 (b), and P (c) on SI of Norway spruce. The gray area comprises $95 \%$ pointwise prognosis intervals; a rug plot shows the distribution of the covariate. The vertical dashed lines mark the
Monotonicity constraints had to be applied to fit ecologically plausible curves that can be used for predictions. A smooth term without any constraints would lead to an increase in SI between 300 and $520 \mathrm{~mm}$, followed by a slight decrease and a further increase until approximately $630 \mathrm{~mm}$. This is in line with the constrained fit. However, a model without constraints would predict a very high SI for very low P_5to9 $(\approx 200 \mathrm{~mm})$ and for high P_5to9 (>630 mm) a steep decrease. Both the dry and the wet margin are barely supported with data, which is also reflected in wide confidence intervals. Therefore, it seems justified to constrain the fit to ecologically plausible behavior at the data margins. Elevation has a strong effect on SI of beech (Fig. 6c). SI is highest at an elevation of about $200 \mathrm{~m}$. It increases from sea level to $200 \mathrm{~m}$ and then continuously decreases. At $400 \mathrm{~m}$, the same SI is reached as that at sea level. Between 450 and $600 \mathrm{~m}$, the otherwise strong decrease is less pronounced. In spite of the high explanatory power of the climate variables and elevation in the model for beech, the
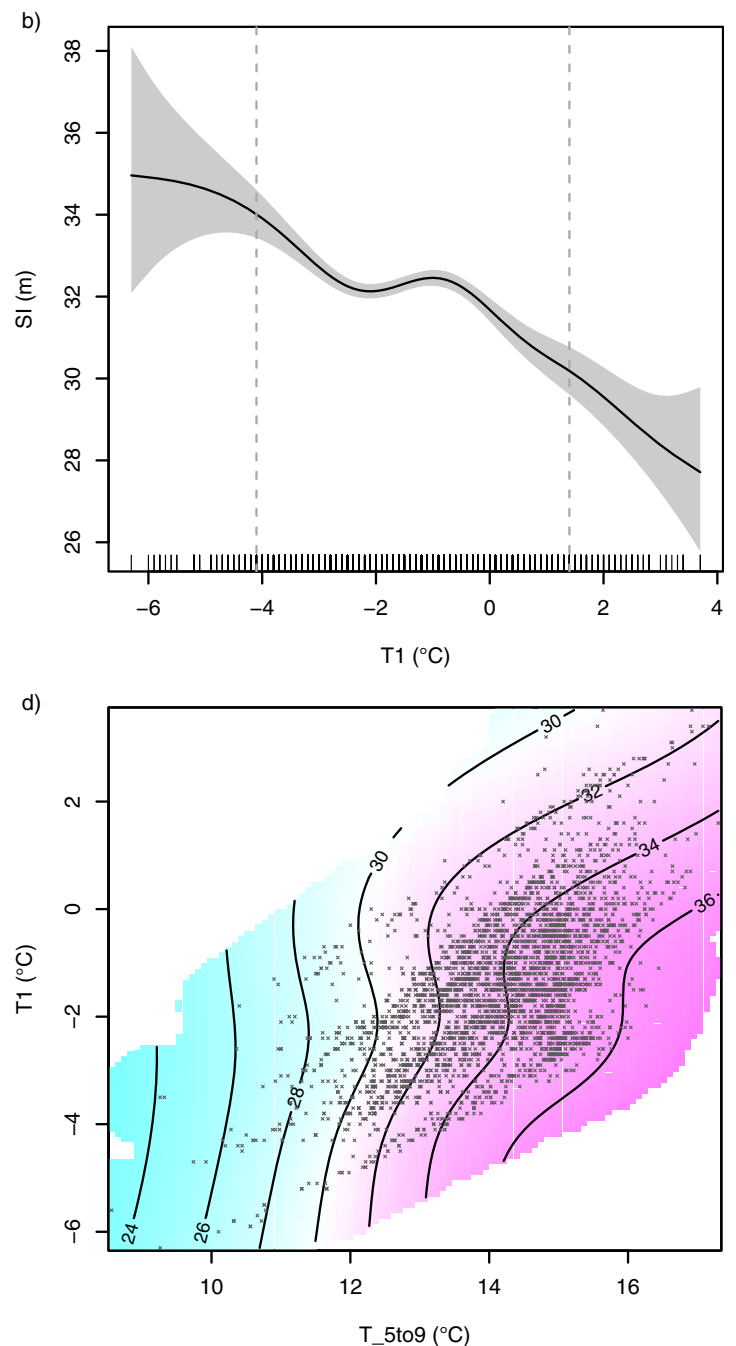

5 and $95 \%$ quantiles of the covariate's distribution. The contour plot (d) shows the result of the alternative model fitted with an interaction between T_5to9 and T1 

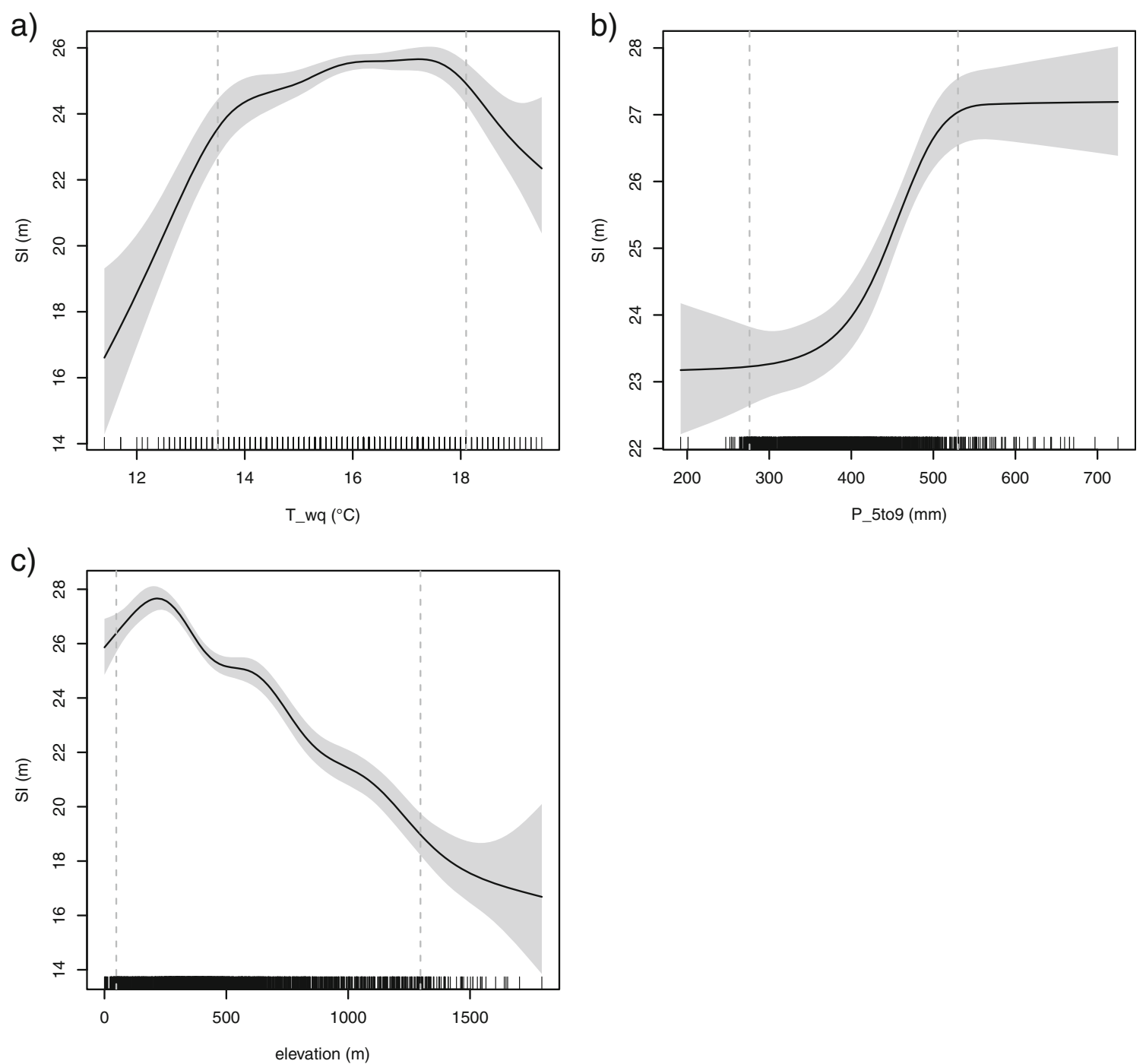

Fig. 6 Effects of T_wq (a), P_5to9 (b) and elevation (c) on SI of European beech. The gray area comprises 95\% pointwise prognosis intervals; a rug plot shows the distribution of the covariate. The vertical dashed lines mark the 5 and $95 \%$ quantiles of the covariate's distribution

effect of the country factor is rather strong (Table 4), predicting approximately $14 \%$ higher SI for Germany under the same environmental conditions.

\subsubsection{Prediction maps}

The models were used to create maps of SI (Fig. 7) for current and future climate (climate scenario RCP 4.5 for the period 2061-2080 based on WorldClim MPI-ESM). After removing plots with extreme soil conditions, we modeled the effect of climate and, in the case of beech, elevation on SI. Thus, prediction maps show the climate-driven SI. We masked the extrapolation range of the models. In these areas, the species can occur but the corresponding climatic conditions were not present in the French and German NFI data used for model fitting (gray areas). Areas in the future maps are hatched when current climatic conditions are present in the training data, but future climatic conditions fall into the extrapolation range.

\subsubsection{Spruce-current climate}

High SI are reached in Southern Germany due to a favorable combination of mean temperature during growing season, temperature in January, and precipitation sum. In the Alps, T 5to9 strongly limits height growth. T 5to9 also acts as a limiting factor in Southeast Finland. The model predicts lower SI for France than for Germany, which is mainly an effect of higher T1. In Eastern Germany P limits height growth. In the Balkans, high SI are predicted in mountain areas because of low $\mathrm{T} 1$ and $\mathrm{P}$ greater than the modeled threshold value of about $750 \mathrm{~mm}$ and suitable T_5to9, but at the highest elevations again, T_5to9 is too low to reach high SI. 

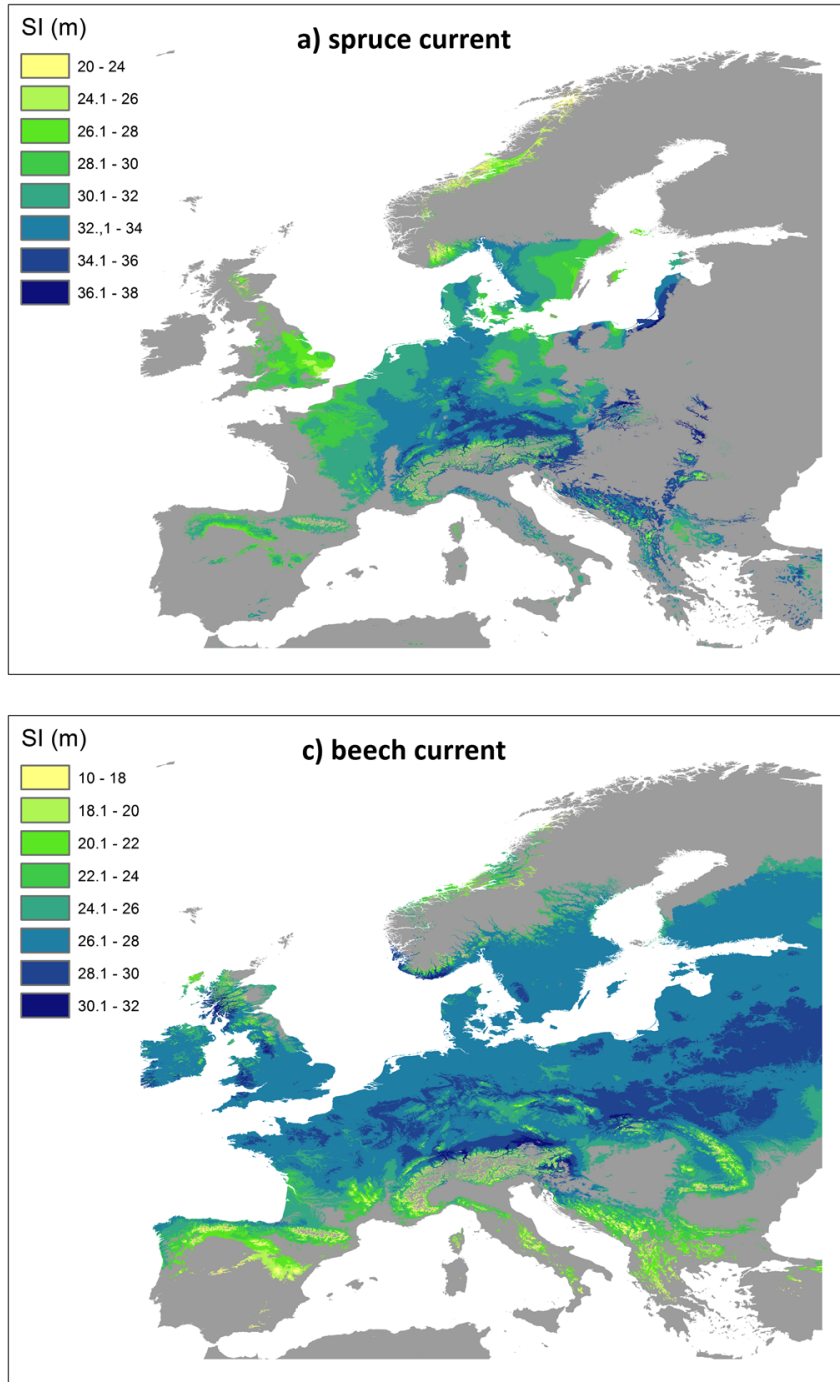

Fig. 7 Map of predicted SI of Norway spruce and European beech for present and future climatic conditions based on plots without extreme soil conditions, i.e., limitations due to soil conditions are not taken into account. The gray areas mask the extrapolation range of the models.

\subsubsection{Spruce - future climate}

As the chosen climate model (MPI-ESM RCP 4.5) predicts a clear increase in temperature but not much change in precipitation, changes in SI are mainly temperature-driven. SI increases in the mountains as T_5to9 increases and no longer limits height growth while $\mathrm{T} 1$ is still rather low. The same is true for Southern Finland, Norway, and the mountain areas in the Balkans. In Germany, the model predicts slightly lower SI mainly due to rising $\mathrm{T} 1$.

\subsubsection{Beech— current climate}

For beech, low SI are predicted for mountainous regions. In the non-masked regions of Southern Europe, low SI are
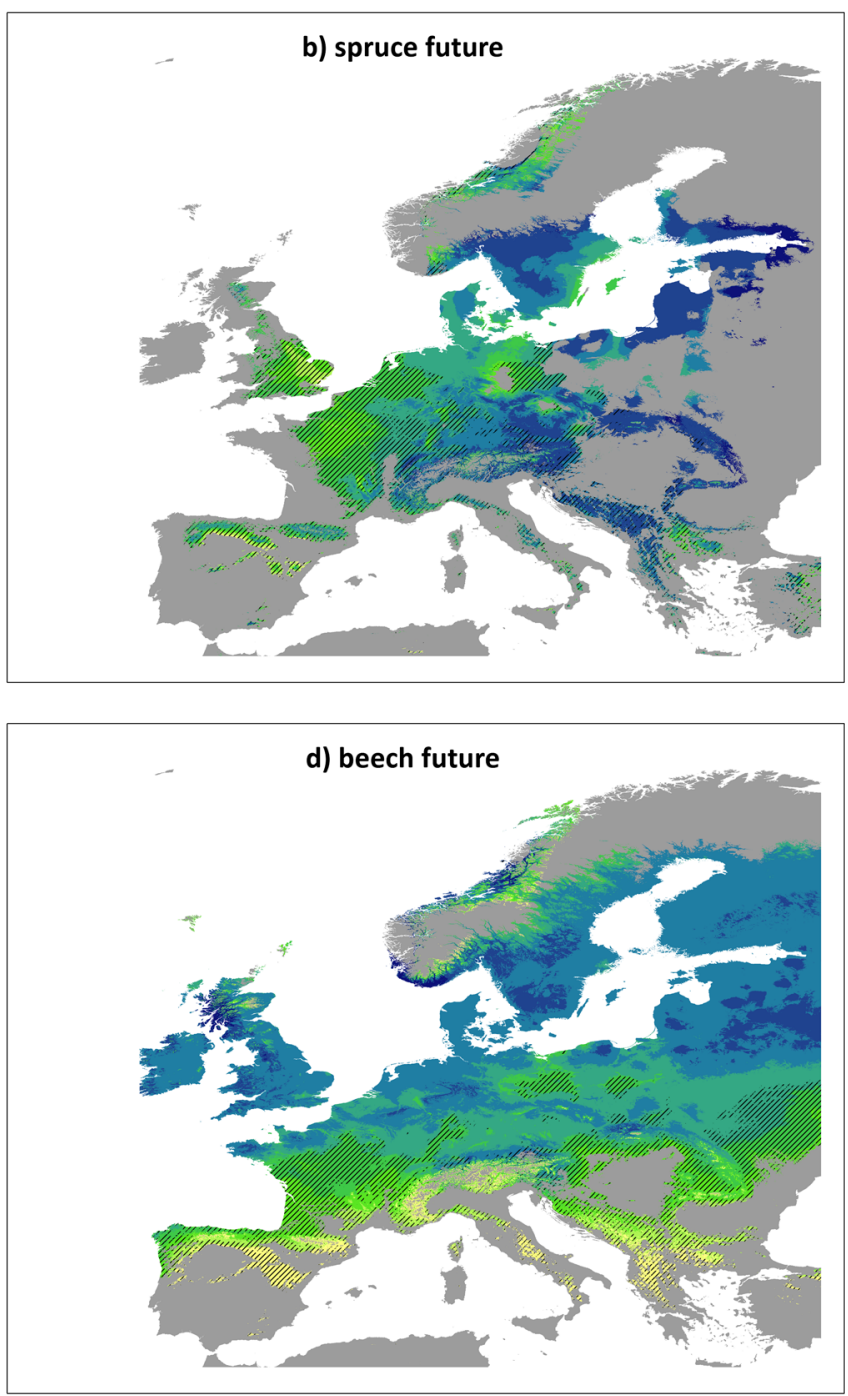

Predictions for the future are hatched when current climatic conditions are present in the training data, but future climatic conditions fall into the extrapolation range

predicted due to elevation and low precipitation. For current climate conditions, summer temperature mostly does not reach values that seriously limit height growth. In the South of Germany, environmental conditions are very favorable for beech and SI is high. Both at the Southern and Northern edge of the non-masked area, a decrease in SI is visible due to high or low T_wq, respectively.

The map of Europe shows the effects caused by the fit of the environmental variables as the country factor was set to zero. However, in the model for beech, the country factor has a strong impact. When taking this factor into account, predicted SI are approximately $14 \%$ higher in Germany than in France, a difference that could not be explained by any of the environmental variables available for selection. 


\subsubsection{Beech—future climate}

In the predictions for the future, the strong effect of elevation in the model becomes apparent. Despite rising temperatures, SI remains low in the mountains. In comparison to the map for current conditions, there is a clear shift to the north for regions of high SI. For Southern Germany, a decrease in SI is predicted. These changes are temperature-driven.

\section{Discussion}

\subsection{Harmonized site indices as a measure for potential productivity}

We propose height of the 100 largest trees - recommended by Assmann (1961) - and corresponding age as stable and sensible measures that can be derived based on a common definition from various inventory sources. Data must allow for distinguishing the top 100 trees and assigning height and age estimates - requirements met by most single-tree-based sampling designs. In comparison to the mid height - the yield table standard for site classes - the top height is relatively robust also in uneven-aged stands, as it is most likely that the 100 largest diameters represent dominant upper canopy trees and it is not affected by thinning from below (Kramer and Akça 1995). Another option would be to choose the Weise height as top height. It is defined as the height corresponding to the root mean square diameter of the top $20 \%$ of diameters of a tree species on a site, which represent dominant trees well throughout the stand's development (Kramer and Akça 1995).

Once harmonized height and age measures have been derived from the inventory data, each plot can be assigned a species-specific static site index based on age and height in relation to lower and upper boundary age-height curves fitted to the data. We employed the Chapman-Richards function which is often used to model growth. It has three directly interpretable growth parameters and shows comparably fast height saturation. However, we did not use it as a growth function. We chose the Chapman-Richards function because it describes well the upper and lower boundary lines of the data which are required to derive static site indices. In this context, the curves fitted might only be interpreted as height growth development as far as cross-sectional data can be interpreted as longitudinal data. But curves fitted to cross-sectional data might be quite different from curves fitted to longitudinal data. Perin et al. (2013), for instance, assert non-saturating height growth for Norway spruce in Belgium from true time series (longitudinal data), while pseudo time series from inventories (cross-sectional data) support saturating height growth
(Dagnelie et al. 1988). Besides the ecophysiological meaning (Ryan and Yoder 1997; Koch et al. 2004), the question of whether stand height saturates or not has a significant effect on the interpretation of data. While non-saturating functions can interpret continued height growth of older stands as an age effect, saturating functions must assume changes in the height asymptote as an effect of changing site conditions. In the end, the static site index does not intend to predict the true trajectory of a stand's top height through time and thus predict the true top height this stand will reach at age 100 . In this sense, the decision to define the static site index by the height at a reference age of 100 years should not be misleading. The statement behind the static site index is NOT what height young stands are to be expected to reach at age 100, BUT what height stands at this site would have reached if they had been planted 100 years ago. As stated in the introduction, the aim of the static site index is to relate site condition data to a stand productivity measure free of age trends. However, changes in silvicultural prescriptions like earlier rotation of fast growing stands can introduce a bias into cross-sectional data, but on the other hand, longitudinal data integrate changing site conditions which surely affect height growth. Evidence for forests in Central Europe suggests accelerated growth over the last decades (Pretzsch et al. 2014; Charru et al. 2014; Spiecker 1999). A promising solution to the dilemma is the interpretation of longitudinal data with dynamic site conditions (Yue et al. 2016). Especially where large-scale inventories permit establishing time seriessuch as the German NFI 1987, 2002, and 2012-the consideration of changing site conditions offers a great potential for future analyses.

The concept of site index was developed for regular, evenaged stands, and the trend to structurally diverse mixed stands and thinning from above reduces the informative value of SI (Pretzsch 2009). We considered this as far as possible in the static site index formation by only including plots where the investigated species accounted for $\geq 70 \%$ of the plot basal area, a threshold that has been used in similar studies based on NFI data (e.g., Seynave et al. 2008; Charru et al. 2014), and by removing plots where the coefficient of variation of age was greater than 0.25. Apart from that, as the developed SI models predict SI independent of stand age and density, they allow comparing site productivity based on environmental conditions and can, for this purpose, be applied to forest systems differing from pure and even-aged stands (Bontemps and Bouriaud 2014).

More generally, the suitability of SI, i.e., the height at a certain age, as an indicator of site productivity can be discussed, as SI is merely an indicator of site productivity, but not a physiological measure and does not completely capture productivity (Skovsgaard and Vanclay 2013; Bontemps and Bouriaud 2014). 
For now, we see the following advantages in our approach. In order to derive a static site index, no repeated measurements are necessary. Top height and static SI are simple measures traditionally used in forestry. Most large-scale inventories provide the required information. SI can then be related to environmental variables. Another option to capture the relationship between productivity and environmental conditions would be to model height in dependence on age and environmental variables in one step (Vallet and Perot 2016; Brandl et al. 2014). In our case, we preferred a two-step approach for two reasons: First, the approach presented in this study allows a mere descriptive site (index) assessment of a stand without the introduction of any modeled effects of environmental variables and all the uncertainty going with it. Thus, the harmonized site index represents the current height growth potential of NFI plots as closely as possible and enables comparisons of different stands without an attempt to explain these differences. In a model that predicts height in dependence on age and environmental variables, the resulting SI range is less similar to the real situation, if the available environmental variables only explain part of the variation in heights, which is often the case. Second, modeling the SI in dependence on environmental variables in a separate step has the advantage that the effect and explanatory power of environmental variables on SI is immediately clear and separated from the effect of age. Our approach also offers the possibility to derive changes in SI from model predictions for current and future conditions and add the modeled trend to the SI calculated at inventory points.

\subsection{Site index dependency on environmental variables}

In a wide temperature range, productivity strongly increases with rising temperatures. This would be expected due to longer growing seasons and higher enzyme activity. Beyond the temperature optimum, a negative effect of further rising temperatures is fitted. For beech, this is obvious in the effect of T_wq. But the effect of temperature is actually similar for spruce. The curve for T_5to9 still slightly increases at the high temperature margin. But as higher temperatures during the growing season usually go in line with higher temperatures in January, which have a negative effect in the spruce model, the overall effect of temperature on SI depends on whether $\mathrm{T}$ 5 to9 or T1 increase more strongly in the future and thus the overall effect might be increasing, decreasing or compensatory. However, the predicted map for spruce productivity in 2061-2080 shows that the joint effect is that of an optimum relationship. Cold temperatures limit growth due to a shorter growing season and reduced enzyme activity. The temperature effect can also be interpreted in relation to the effect of water supply. At high temperatures, droughts are more likely and photosynthesis stops due to water shortage. Apart from the interconnection with the whole temperature regime, the effect of T1 in the spruce model might be explained with the necessity to put more resources in defense mechanisms (Matyssek et al. 2012). Different provenances might also play a role (Tollefsrud et al. 2008). The effect of precipitation is described by a saturation curve. Above a given amount of water, precipitation is no longer the limiting factor. In the spruce model, this effect is very stable and clear. It depends little on the chosen temperature variables and allows deriving a threshold value of about $750 \mathrm{~mm}$ of annual precipitation below which productivity is reduced. For beech, productivity strongly decreases when precipitation sum during growing season falls below $500 \mathrm{~mm}$.

The effect of the country factor in the spruce model is negligible. In contrast, in the beech model, productivity in France is distinctly lower than that in Germany. We introduced this factor in order to take possible differences in inventory design into account. For instance, it might be an effect of the difference in age estimation. However, it does not seem likely that the difference is so strong for beech whereas it is very low for spruce. In addition, the filtering of the data (e.g., discarding plots with no defined forest structure or coppice plots) should prevent this. In the South of France, small, unproductive beeches can be found, as beech is quite sensitive to drought and well adapted to climates with high atmospheric humidity, which are more likely in Germany. However, the climate variables offered in variable selection did not capture these differences completely (neither did continentality or aridity indices). We had to include elevation in the beech model for a much better explanation of differences in productivity. Above $200 \mathrm{~m}$, there is a strong negative effect of elevation. The downside is that such a model is less apt to predict productivity for future climate scenarios, as the effect of elevation partly absorbs the climate effect and is (apart from different soil conditions and wind speed) in fact a climate effect. This becomes obvious in the map for beech productivity in 20612080, where productivity remains low in mountain areas even with rising temperatures. Other possible explanations for the differences between the two countries could be differences in provenance, management, soil conditions, and nitrogen deposition. Nitrogen deposition, for instance, is higher in Germany than in France (Michel and Seidling 2017). As the factor country is not considered for predictions on the European scale, actual SI in Germany is higher than in the maps shown for Europe. Thus, if the focus is on Germany or France instead of the whole Europe, taking the country factor into account provides more accurate and realistic predictions. However, the climate trend, i.e., the magnitude and direction of the changes in SI, is not affected by the country factor.

Albert and Schmidt (2010) fit an effect similar to the effect of precipitation in our study for precipitation during the growing season in their SI model for Norway spruce and water balance in 
their model for European beech. Their results show an increasing SI with rising temperatures during growing season and a slowdown at high temperatures. In contrast, in our study not only a slow-down but even a decline in SI at the warm margin is suggested. Our database extends much further to the warm margin (T_5to9 for spruce: $97.5 \%=16^{\circ} \mathrm{C}$ and $\max .=17.3{ }^{\circ} \mathrm{C}$; T_5to9 for beech: $97.5 \%=16.7{ }^{\circ} \mathrm{C}$ and $\max .=18.3{ }^{\circ} \mathrm{C}$ ) whereas the maximum in the data of Albert and Schmidt lies only at $15.4^{\circ} \mathrm{C}$ for both spruce and beech. Nothdurft et al. (2012) fit an optimum relationship between temperature during growing season as well as a limitation of growth at low precipitation during growing season for both beech and spruce. In the spruce model containing climate variables of Seynave et al. (2005), SI decreases with a fall in spring temperature and with a summer climatic water deficit. For beech, Seynave et al. (2008) find that both cold temperatures at the beginning of the growing season as well as high July temperatures limit SI, which is expressed in the effect of T_wq in our beech model. On the whole, our findings are well in line with results from other studies carried out in Germany and France. Rising temperatures will first lead to an increase in productivity as long as water supply is not limiting. Above an optimum range, a further increase in temperature has no positive effect on productivity anymore and can even lead to a decline in SI as water shortage becomes more likely and respiration increases more strongly than assimilation (Schultz 2002).

Nineteen percent of the variation in SI of spruce and $40 \%$ of the variation of SI in beech can be explained by the SI models. At first glance, this seems small, but it is not surprising, as tree growth is a complex process and there are many influences that we could not take into account considering our database and method. For instance, even after having removed plots with extreme soil conditions, the influence of physical and chemical soil conditions on growth might be considerable (Mellert and Ewald 2014; Prietzel et al. 2008) and thus models including soil parameters - especially if these are not interpolated but measured at the plot-achieve higher explanatory power (e.g., Seynave et al. 2005). We only used easily available mean climate parameters, but of course, the influence of climate on growth is much more complex and growth is not only shaped by average conditions but also by extreme events like droughts (Bréda et al. 2006). Further reasons for a reduced goodness of fit might be found in an insufficient accuracy of climate data and in spatial genetic differentiations of a tree species (Bontemps and Bouriaud 2014). Nitrogen deposition, which has been identified as an important factor behind observed growth trends (Pretzsch et al. 2014; Yue et al. 2016), might partly account for unexplained differences in productivity. In addition, not only on the side of the explanatory variables, but also on the side of the response, there is uncertainty involved due to sampling design, errors in age estimation and height measurements, which we analyze and discuss in detail in Appendix 1.

Still, the models can explain a remarkable part of variation in SI (for beech, comparable to the model of Albert and
Schmidt 2010, which includes soil parameters and spatial effects, and distinctly higher than the model of Nothdurft et al. 2012; for spruce, those of Albert and Schmidt 2010 achieve an $R^{2}$ of 0.39 and Nothdurft et al. an $R^{2}$ of 0.32 , but these models include soil parameters, nitrogen deposition, and spatial effects or stand characteristics and elevation respectively). As the climate effects are ecologically plausible, the models can be used to assess changes in site productivity due to changes in climatic conditions. Even if SI prediction might be over- or underestimated due to regression to the mean, the differences between predicted SI for present conditions and future scenarios are clear and give an indication of the changes in productivity that might be expected for the species in the future. In the end, our approach is not intended to predict exact heights, but to compare stands and assess trends in productivity. Still, the maps have to be interpreted carefully, as they include both the uncertainty in the modeled effects as well as the uncertainty in the climate scenarios.

It also needs to be emphasized that the first step of our approach, the determination of a static site index as a measure for productive potential, is independent of the SI models presented here. The static site index can be used as a stand-alone method to assess and compare current stands. And of course, it can function as a response variable in models containing better explanatory variables and thus achieving higher predictive power.

\section{Conclusion}

Data from national forest inventories are becoming increasingly accessible for science and the public. They offer tremendous potential to enhance our understanding of tree species' distribution and growth potential. When combining different national forest inventories, a relatively simple measure for the growth potential is needed. A static site index can be calculated whenever data allow for distinguishing a top collective and assigning height and age estimates. Based on this, a harmonized site index could be derived from joint French and German NFI data. Virtual stands constituted a helpful tool in estimating height and age errors and their propagation in the site index. Explaining static site index from basic climate data resulted in simple and robust models that can be applied to climate change scenarios.

One premise to exploit the potential of NFI data to enhance our understanding of tree species' distribution and growth potential is the existence of reliable site data. Currently, data sets like WorldClim (Hijmans et al. 2005) or the European soil data base (JRC 2001-2016) provide harmonized site data with comparably high resolution of $1 \mathrm{~km}$ - approximately the resolution of the inventory coordinates. Still, neither the parameter set nor the spatial and temporal resolution, in the case of climate, appear satisfying, especially in mountainous terrain. 
Efforts like the environmental data base to the German NFI "staoDB" (this virtual issue) or the "ecologie" files to the French NFI are necessary and at the same time still require harmonization.

Acknowledgements We would like to thank the Thünen Institute of Forest Ecosystems and the Institut national de l'information géographique et forestière (IGN) for providing the NFI data. The study was funded by the Federal Ministry of Food and Agriculture and the Federal Ministry for the Environment, Nature Conservation, Building and Nuclear Safety of Germany in the frame of the Waldklimafonds. We would like to thank our partners in the project "Forest productivity - carbon sequestration - climate change" for the successful collaboration as well as the anonymous reviewers for their constructive criticism.

Funding The work is part of the project WP-KS-KW (Waldproduktivität, Kohlenstoffspeicherung, Klimawandel; engl: Forest productivity, carbon sequestration, climate change) and was funded in the frame of the Waldklimafonds by the Federal Ministry of Food and Agriculture and the Federal Ministry for the Environment, Nature Conservation, Building and Nuclear Safety of Germany.

\section{Compliance with ethical standards}

Conflict of interest The authors declare that they have no conflict of interest.

\section{Appendix 1: Error estimation from virtual data}

The uncertainties afflicted with height, age, and site indices are assessed using a dataset of virtual stands based on yield table characteristics. Comparisons of samples, drawn from the virtual dataset according to different sampling designs, present a tool to check that the combination of different NFIs is justified.

\section{Methods}

To obtain an error estimate of the site index in terms of bias and variance, we simulated DBH-height distributions assuming a given DBH variance and a DBH-dependent height variance. We used the stand biometrics of yield tables for Norway spruce of Assmann and Franz (1963, medium yield level) to create virtual stands of 1 ha. These yield tables comprise stand parameters for six site classes over an age range of 20 to 120 years. To create the virtual stands the stem number $N$ per hectare, the root mean square diameter $d_{\mathrm{q}}$ and the corresponding height $h_{\mathrm{q}}$ were needed. DBH distributions were generated by drawing $\mathrm{N}$ samples from $d_{q}$-dependent Weibull functions (Nagel and Biging 1995):

$f(x)=\left(\frac{a}{b}\right) *\left(\frac{x}{b}\right)^{(a-1)} * \exp \left(-\left(\frac{x}{b}\right)^{a}\right)$

with $x=D B H-7$ and the shape parameter $a=3.4+0.35$ $*\left(d_{q}-7\right)-0.247 * d_{q}$ and the scale parameter $b=-2.5+$
$1.1 *\left(d_{q}-7\right)$. To fit the tabulated $d_{\mathrm{q}}$, the resulting DBH distribution was corrected for the small offset. Heights were simulated based on diameters by using uniform height-diameter curves (Sloboda et al. 1993):

$h_{i}=1.3+\left(h_{q}-1.3\right) * \exp \left(-\left(b 0+b 1 * d_{q}\right) *\left(1 / D B H_{i}-1 / d_{q}\right)\right)+\varepsilon(0, \sigma)$

where $(0, \sigma)$ represents a normally distributed error with a mean of zero and a standard deviation $\sigma=b s 0+b s 1 *$ $\log (s d(D B H))$ with $b \mathrm{~s} 0=0.14$ and $b \mathrm{~s} 1=0.56$.

The effect of stand density on the site index determination was quantified by randomly setting stem number to $20,40,60$, 80 , or $100 \%$ of the original value from the yield table.

From the virtual stand, one sample according to the sampling method of the German NFI and one sample according to the sampling method of the French NFI were drawn. In the German NFI, the sampling probability $p_{G}$ of each tree depends on its basal area and the basal area factor $z f=4$ :

$p_{G}=\pi^{*} \frac{\mathrm{DBH}^{2}}{40000 * z f}$

In the French NFI, the sampling probability $p_{F}$ of each tree depends on the size of the concentric circle corresponding to its DBH:

$p_{F}=\left\{\begin{array}{l}\pi^{*} \frac{6^{2}}{10000} \text { for } 7.5 \mathrm{~cm} \leq D B H<22.5 \mathrm{~cm} \\ \pi^{*} \frac{9^{2}}{10000} \text { for } 22.5 \mathrm{~cm} \leq D B H<37.5 \mathrm{~cm} \\ \pi^{*} \frac{15^{2}}{10000} \text { for } 37.5 \mathrm{~cm} \leq D B H\end{array}\right.$

Now, the sampling design of the German and French NFI can be simply imitated by drawing random numbers from a uniform distribution between 0 and 1 : if the sampling probability $p$ of the tree is bigger than the number drawn, the tree is included in the sample. The heights of the sample trees were calculated from species-specific uniform height-diameter curves adding a random error term as in Albert (2000). From these heights, a maximum of three (if available) trees were chosen to represent the actually "measured height." The heights of the sample trees were calculated from speciesspecific uniform height-diameter curves based on the "measured" heights.

To estimate the error of $d_{\text {top }}$ and $h_{\text {top }}$ due to the sampling design, the procedure was repeated 1000 times whereby site classes and age spectrum of the yield table were sampled at random. This resulted in a dataset of 1000 virtual stands and 1000 samples according to the German NFI sampling method and 1000 samples according to the French NFI sampling method. The error, i.e., the difference in the $d_{\text {top }}$ and $h_{\text {top }}$ estimates from the inventory sampling 
and the true $d_{\text {top }}$ and $h_{\text {top }}$ of the entire stand, can be quantified in terms of root mean squared error (RMSE) and bias. Bias was determined by least squares regression without intercept of true $d_{\text {top }}$ (or $h_{\text {top }}$ ) against $d_{\text {top }}$ (or $h_{\text {top }}$ ) estimates from the inventory sampling.

In order to assess the influence of age errors on SI estimation, the Chapman-Richards-functions for the upper and the lower boundary line of Norway spruce were used. True SI between 20 and $40 \mathrm{~m}$ in $4 \mathrm{~m}$-steps were assumed. Based on these true SI, true heights for each age in 5-year-steps from 20 and 120 years were derived. Measurements afflicted with age errors were simulated by subtracting/adding the absolute value of a random error from $\mathrm{N}(0,5)$ from/to the trues ages, but maintaining the true heights. The difference between true SI and the SI estimation for the simulated measurement afflicted with age error was calculated and averaged over 1000 repetitions.

\section{Results}

Since height variance between the trees in a stand is typically lower than the diameter variance, the bias and vari- ance of the determined top height $h_{\text {top }}$ are smaller than for the $d_{\text {top. }}$. The correlation between the measure calculated from the stand and the measure calculated from the sample is very high (NFI Germany: 0.991, NFI France: 0.996) and the bias is negligible (NFI Germany: 1.014, NFI France: 1.009) (Fig. 8a). This ensures that there are no systematic deviations resulting from the two sampling methods. Furthermore, $h_{\text {top }}$ is relatively stable with respect to effects of density. Although SI is slightly underestimated at all densities, the difference is always lower than $0.8 \mathrm{~m}$ (Fig. 8a) and the standard deviation is less than $1.2 \mathrm{~m}$. Figure $8 \mathrm{~b}$ shows that there is no big or systematic deviation between French and German NFI samples at all.

As the second possible error source in the site index estimation, we investigated the effect made by under- or overestimating stand age. As Fig. 8c shows, an underestimation of age leads to an overestimation of the site index of about $2 \mathrm{~m}$ at age 40 which decreases to about $0.25 \mathrm{~m}$ at age 100 . Likewise, an overestimation of age leads to a slightly lower underestimation of the site index of about $1.6 \mathrm{~m}$ at age 40 and $0.2 \mathrm{~m}$ at age 100 . a)

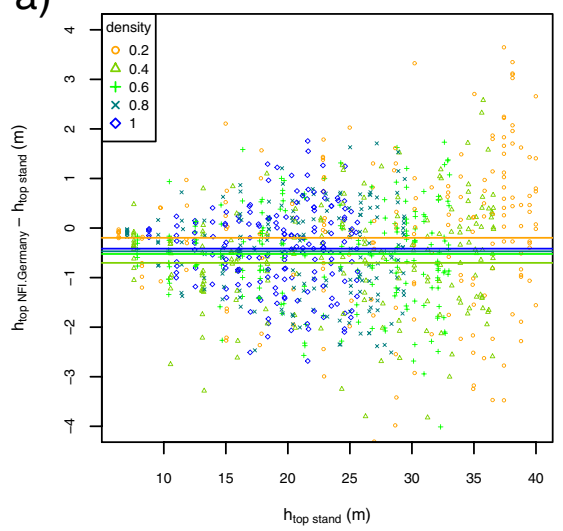

b)

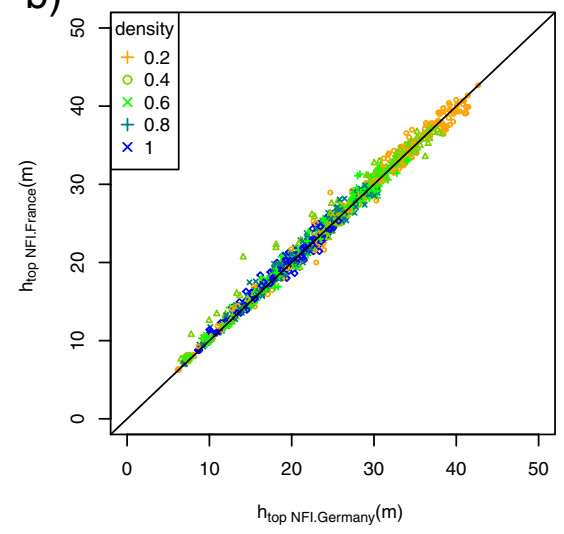

c)

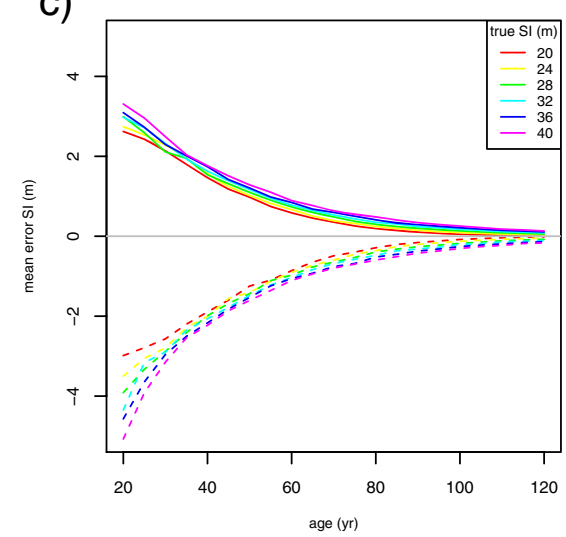

Fig. 8 a Difference between the true stand $h_{\text {top }}$ and the calculated $h_{\text {top }}$ from the German NFI sample in dependence on the true stand $h_{\text {top }}$ for different relative stand densities. The lines mark the mean differences for each stand density. b Comparison between $h_{\text {top }}$ calculated from the German NFI sample and $h_{\text {top }}$ calculated from the French NFI sample. c
Assuming a true SI the upper lines show the error in SI estimation for an assumed overestimation of age, the lower dashed lines show the error in SI estimation for an assumed underestimation of age using the ChapmanRichards functions for Norway spruce

\section{Appendix 2: Static site indices for Norway spruce, European beech, Douglas-fir, Scots pine, sessile oak, and pedunculate oak}

Besides Norway spruce and European beech, static site indices were derived for four other common species: Scots pine, Douglas-fir, sessile oak, and pedunculate oak. Thus, we show that the method is applicable to a wide range of species and are able to compare the species' growth potential.
Figure 9 displays age-height scatter plots and the fits of the Chapman-Richards function for the six investigated species from the joint data sets of the German and French NFI. For Douglas-fir, there are only few measurements available for ages $>70$ years, and for the other species, ages up to at least 130 years are well represented. Table 5 summarizes the function parameters for the joint data set. As can be clearly seen in Fig. 9, the species with the highest growth potential is Douglas-fir, followed by Norway spruce. This is also 
a)

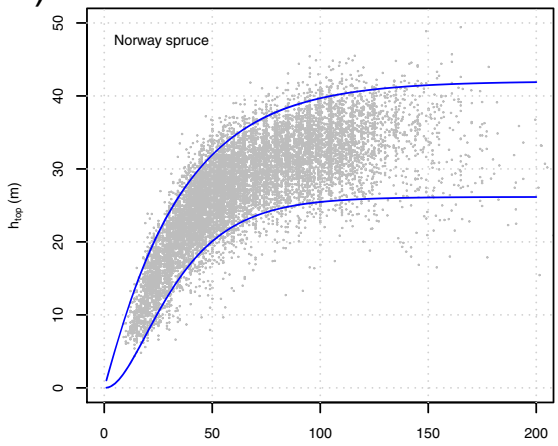

d)

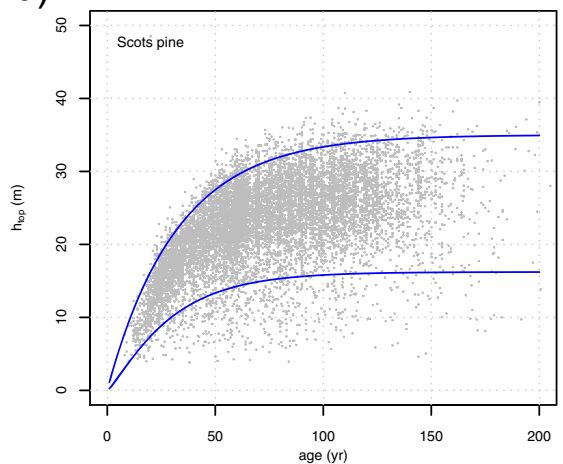

b)

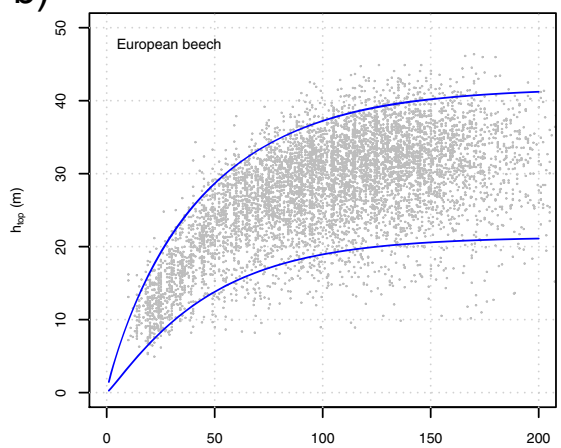

e)

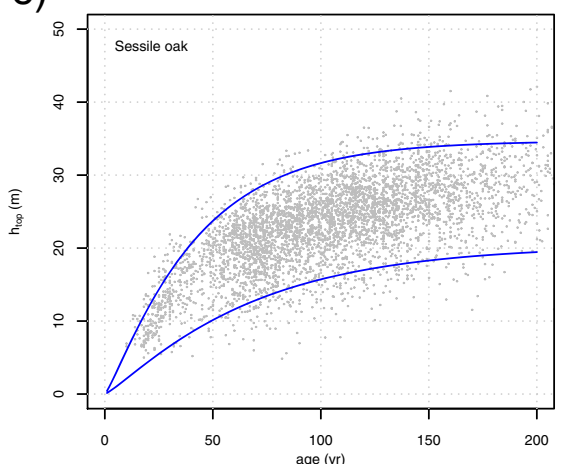

c)

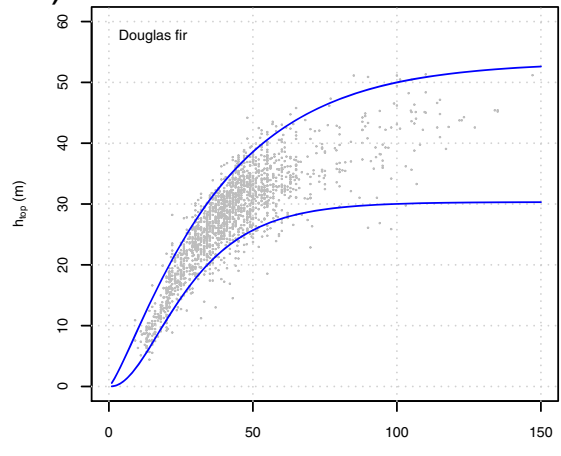

f)

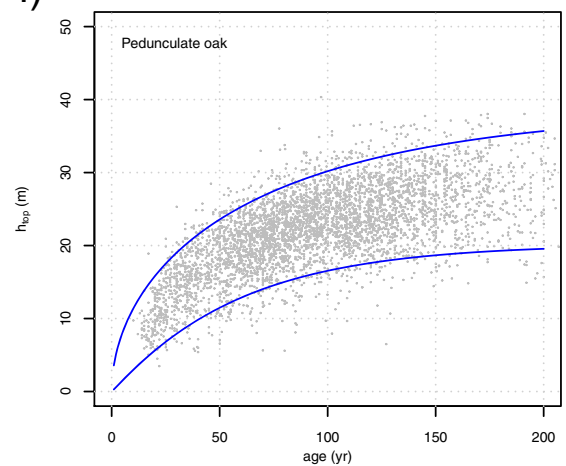

Fig. 9 Age-height scatter plots for the six investigated tree species in the German and French NFI data: a Norway spruce, b European beech, c depict quantile regression for the $5 \%$ and $95 \%$ percentiles with the Chapman-Richards function

Table 5 Results of fitting the Chapman-Richards function to the lower 5\% and the upper 95\% percentiles of the age-height distribution for the joint German and French inventory data

\begin{tabular}{lllllllll}
\hline Variable & Quantile curve & Parameter/function & Spruce & Beech & Pine & Douglas-fir & Sessile oak & Pedunculate oak \\
\hline Sample size & & $N$ (Germany) $=$ & 10,552 & 5247 & 9693 & 1045 & 1929 & 1647 \\
& & $N$ (France) $=$ & 914 & 1595 & 1372 & 768 & 2475 & 2844 \\
Chapman-Richards & Lower & $A=$ & 26.16 & 21.35 & 16.22 & 30.33 & 20.37 & 20.18 \\
(CR) & & $k=$ & 0.0448 & 0.0232 & 0.0390 & 0.0553 & 0.0164 & 0.0176 \\
& & $p=$ & 2.35 & 1.15 & 1.28 & 2.54 & 1.2 & 1.05 \\
& \multirow{2}{*}{ Upper } & $A=$ & 42.01 & 41.79 & 35.01 & 53.37 & 34.69 & 38.80 \\
& & $k=$ & 0.0294 & 0.0208 & 0.0304 & 0.0301 & 0.0261 & 0.0095 \\
& & $p=$ & 1.05 & 0.86 & 0.98 & 1.29 & 1.2 & 0.51 \\
\hline
\end{tabular}

represented by the fitted asymptotes (A) of the upper boundary line in Appendix Table 5.

\section{References}

Albert M (2000) Ein funktionalisierter Höhenergänzungsalgorithmus für Einzelbaumwachstumsmodelle. Jahrestagung der Sektion Ertragskunde des DVFFA in Kaiserslautern, 05.-07.06.2000:32-43
Albert M, Schmidt M (2010) Climate-sensitive modelling of siteproductivity relationships for Norway spruce (Picea abies (L.) Karst.) and common beech (Fagus sylvatica L.). For Ecol Manag 259:739-749

Assmann E (1961) Waldertragskunde. Organische Produktion, Struktur, Zuwachs und Ertrag von Waldbeständen. BLV Verlagsgesellschaft, München, Bonn, Wien

Assmann E, Franz F (1963) Vorläufige Fichten-Ertragstafel für Bayern, München

BMELV Bundesministerium für Ernährung, Landwirtschaft und Verbraucherschutz (2011) Aufnahmeanweisung für die dritte Bundeswaldinventur $\left(\mathrm{BWI}^{3}\right)$ (2011-2012) 
Bontemps J-D, Bouriaud O (2014) Predictive approaches to forest site productivity: recent trends, challenges and future perspectives. Forestry 87:109-128

Brandl S, Falk W, Klemmt H-J, Stricker G, Bender A, Rötzer T, Pretzsch H (2014) Possibilities and limitations of spatially explicit site index modelling for spruce based on National Forest Inventory Data and Digital Maps of Soil and Climate in Bavaria (SE Germany). Forests 5:2626-2646

Bréda N, Huc R, Granier A, Dreyer E (2006) Temperate forest trees and stands under severe drought: a review of ecophysiological responses, adaptation processes and long-term consequences. Ann For Sci 63:625-644

Brus DJ, Hengeveld GM, Walvoort DJJ, Goedhart PW, Heidema AH, Nabuurs GJ, Gunia K (2012) Statistical mapping of tree species over Europe. Eur J For Res 131:145-157

Charru M, Seynave I, Hervé J-C, Bontemps J-D (2014) Spatial patterns of historical growth changes in Norway spruce across western European mountains and the key effect of climate warming. Trees 28:205-221

Conrad V (1946) Usual formulas of continentality and their limits of validity. Eos 27:663-664

Dagnelie P, Palm R, Rondeux J, Thill A (1988) Tables de production relatives à l'épicéa commun (Picea abies KARST.). Les presses agronomique de Gembloux, Gembloux

Dahm S (2006) Auswertungsalgorithmen für die zweite Bundeswaldinventur. Arbeitsbericht des Instituts für Waldökologie und Waldinventuren Nr. 2006 / 1, Eberswalde

Dolos K, Mette T, Wellstein C (2016) Silvicultural climatic turning point for European beech and sessile oak in Western Europe derived from national forest inventories. For Ecol Manag 373: $128-137$

Eichhorn F (1902) Ertragstafeln für die Weißtanne. Springer, Berlin

Gehrhardt E (1909) Über Bestandeswachstumsgesetze und ihre Anwendung zur Aufstellung von Ertragstafeln. Allgemeine Forstund Jagdzeitung 85:117-128

Hijmans RJ, Cameron SE, Parra JL, Jones PG, Jarvis A (2005) Very high resolution interpolated climate surfaces for global land areas. Int $\mathrm{J}$ Climatol 25:1965-1978

IGN Institut national de l'information géographique et forestière Inventaire forestier national (IFN). http://inventaire-forestier.ign.fr. Accessed 13 Oct 2016

JRC - Joint Research Centre, European Soil Data Centre ESDAC (20012016) European soil database and soil properties. http://eusoils.jrc. ec.europa.eu/resource-type/datasets. Accessed 13 Oct 2016

Koch GW, Sillett SC, Jennings GM, Davis SD (2004) The limits to tree height. Nature 428:851-854

Kramer H, Akça A (1995) Leitfaden zur Waldmesslehre, 3rd edn. J.D. Sauerländer's Verlag, Frankfurt/M

Matyssek R, Schnyder H, Oßwald W, Ernst D, Munch C, Pretzsch H (eds) (2012) Growth and defence in plants. Ecol Studies 220. Springer-Verlag, Heidelberg

McRoberts RE, Tomppo EO, Schadauer K, Ståhl G (eds) (2012) Special issue on COST action E43: harmonizing National Forest Inventories: (editorial +10 articles). For Sci 58

Mellert KH, Ewald J (2014) Nutrient limitation and site-related growth potential of Norway spruce (Picea abies [L.] Karst) in the Bavarian Alps 133:433-451

Michel A, Seidling W (eds) (2017) Forest condition in Europe: 2017 technical report of ICP forests. Report under the UNECE convention on long-range transboundary air pollution (CLRTAP). BFWDokumentation 24/2017. Vienna: BFW Austrian Research Centre for Forests. 128 p

Nabuurs GJ, Lindner M, Verkerk PJ, Gunia K, Deda P, Michalak R, Grassi G (2013) First signs of carbon sink saturation in European forest biomass. Nat Clim Chang 3:792-796
Nagel J, Biging GS (1995) Schätzung der Parameter der WeibullFunktion zur Generierung von Durchmesserverteilungen. Allgemeine Forst- und Jagdzeitung 166:185-189

Nothdurft A, Wolf T, Ringeler A, Böhner J, Saborowski J (2012) Spatio-temporal prediction of site index based on forest inventories and climate change scenarios. For Ecol Manag 279: $97-111$

Perin J, Hébert J, Brostaux Y, Lejeune P, Claessens H (2013) Modelling the top-height growth and site index of Norway spruce in Southern Belgium. For Ecol Manag 298:62-70

Pickett STA (1989) Space-for-time substitution as an alternative to long-term studies. In: Likens GE (ed) Long-term studies in ecology: approaches and alternatives. Springer New York, New York, pp 110-135

Pott M (1997) Wachstum der Fichte in Bayern. Auswertung von Daten der Forsteinrichtungsdatenbank der Bayerischen Staatsforstverwaltung. Diploma thesis, LMU München

Pretzsch H (2009) Forest dynamics, growth and yield. Springer, Heidelberg

Pretzsch H, Biber P, Schütze G, Uhl E, Rötzer T (2014) Forest stand growth dynamics in Central Europe have accelerated since 1870. Nat Commun 5:4967

Prietzel J, Rehfuess KE, Stetter U, Pretzsch H (2008) Changes of soil chemistry, stand nutrition, and stand growth at two Scots pine (Pinus sylvestris L.) sites in Central Europe during 40 years after fertilization, liming, and lupine introduction. Eur J For Res 127:43-61

Pya N, Wood SN (2015) Shape constrained additive models. Stat Comput 25:543-559

Richards FJ (1959) A flexible growth function for empirical use. J Exp Bot 10:290-301

Röhle H (1997) Änderung von Bonität und Ertragsniveau in südbayerischen Fichtenbeständen. Allg Forst- u.J.-Ztg 168:110-114

Ryan MG, Yoder BJ (1997) Hydraulic limits to tree height and tree growth. Bioscience 47:235-242

Schober R (1995) Ertragstafeln wichtiger Baumarten bei verschiedener Durchforstung, 4th edn. Sauerländer, Frankfurt am Main

Schultz J (2002) Ökozonen der Erde, Engl. edn. The ecozones of the World. Ulmer, Stuttgart, p 58

Seynave I, Gégout JC, Hervé JC, Dhôte JF, Drapier J, Bruno É, Dumé G (2005) Picea abies site index prediction by environmental factors and understorey vegetation: a two-scale approach based on survey databases. Can J For Res 35:1669-1678

Seynave I, Gégout JC, Hervé JC, Dhôte JF (2008) Is the spatial distribution of European beech (Fagus sylvatica L.) limited by its potential height growth? J Biogeographica 35:1851-1862

Skovsgaard JP, Vanclay JK (2008) Forest site productivity: a review of the evolution of dendrometric concepts for even-aged stands. Forestry 81:13-31

Skovsgaard J, Vanclay JK (2013) Forest site productivity: a review of spatial and temporal variability in natural site conditions. Forestry 86:305-315

Sloboda B, Gaffrey D, Matsumura N (1993) Regionale und lokale Systeme von Höhenkurven für gleichaltrige Waldbestände. Allgemeine Forst- und Jagdzeitung 164:225-229

Spiecker H (1999) Overview of recent growth trends in European forests. Water Air Soil Pollut 116:33-46

Tollefsrud MM, Ro K, Gugerli F, Johnsen Ø, Skrøppa T, Cheddadi R, Wo VDK, Latałowa M, Terhürne-Berson R, Litt T, Geburek T, Brochmann C, Sperisen C (2008) Genetic consequences of glacial survival and postglacial colonization in Norway spruce: combined analysis of mitochondrial DNA and fossil pollen. Mol Ecol 17: $4134-4150$

Tomppo E, Gschwantner T, Lawrence M, McRoberts RE (eds) (2010) National Forest Inventories: pathways for common reporting. Springer Netherlands, Dordrecht 
Vallet P, Perot T (2016) Tree diversity effect on dominant height in temperate forest. For Ecol Manag 381:106-114

Vannière B (1984) Tables de production pour les forêts françaises. ENGREF, 158p

Venables WN, Ripley BD (2002) Modern applied statistics with S, 4th edn. Statistics and Computing. Springer, New York von Baur F (1881) Das Forstl. Versuchswesen. Band I, Augsburg 359 p Wood S (2006) Generalized additive models: an introduction with R. Chapman and Hall/CRC, Boca Raton

Yue C, Kahle H-P, von Wilpert K, Kohnle U (2016) A dynamic environment-sensitive site index model for the prediction of site productivity potential under climate change. Ecol Model 337:48-62 